\title{
The effectiveness of group positive psychotherapy on depression and happiness in breast cancer patients: A randomized controlled trial
}

Mohammad Mehdi Dowlatabadi ${ }^{1}$, Seyed Mojtaba Ahmadi ${ }^{2}$, Mohammad Hossein Sorbi ${ }^{1}$, Omid Beiki ${ }^{3}$, Tayebeh Khademeh Razavi ${ }^{4}$, Reza Bidaki ${ }^{5,6}$

${ }^{1}$ M.Sc. of Clinical Psychology, Department of Psychology, Faculty of Medicine, Kermanshah University of Medical Science, Kermanshah, Iran

2 Ph.D. Student of Clinical Psychology, Department of Psychology, Faculty of Medicine, Shahid Beheshti University of Medical Science, Tehran, Iran

${ }^{3}$ MD. of Epidemiology, Assistant Professor, Department of Epidemiology, Faculty of Medicine, Kermanshah University of Medical Science, Kermanshah, Iran

${ }^{4}$ Ph.D. Student of Educational Psychology, Department of Psychology, Islamic Azad University Marvdasht Branch, Shiraz, Iran

${ }^{5}$ MD. of Psychiatrist, Associate Professor, Research Center of Addiction and Behavioral Sciences, Shahid Sadoughi University of Medical Sciences, Yazd, Iran

${ }^{6}$ MD. Psychiatrist, Associate Professor, Research Center of Diabetes, Shahid Sadoughi University of Medical Sciences, Yazd, Iran

\section{Type of article: Original}

\begin{abstract}
Background: Breast cancer is one of the most prevalent cancers in women in the world. It causes fear, despair, and takes a tremendous toll on psychological status.

Objective: To determine the effectiveness of group positive psychotherapy on the depression and happiness of breast cancer patients.

Methods: This randomized controlled trial was conducted with 42 breast cancer patients in The Oncology Center at Kermanshah, Iran in 2015. The Data were gathered before intervention and ten weeks afterwards. The data were collected using Beck's Depression Inventory (BDI-II) and Oxford's happiness Inventory (OHI). The data were analyzed by SPSS-16, Kolmogorov-Smirnov (K-S), chi-squared, and multivariate analysis of covariance (MANCOVA).

Results: The results showed a significant reduction in the depression of the group on positive psychotherapy compared with the control group. Also the positive psychotherapy group experienced a significant increase in the patients' happiness, while there was no significant increase in the control group.

Conclusion: The results of this research showed the effectiveness of positive psychotherapy on the reduction of mental pressure and the improvement of the mental status of breast cancer patients. This economical therapy can be used to increase patients' psychological health.

Clinical Trial Registration: The trial was registered at the Iranian Registry of Clinical Trials (IRST) with the identification number IRCT2013101410063N4.

Funding: The authors received financial support for the research from Kermanshah University of Medical Sciences.

Keywords: positive psychotherapy, depression, happiness, breast cancer
\end{abstract}

\section{Corresponding author:}

Mohammad Hossein Sorbi, Department of Psychology, Faculty of Medicine, Kermanshah University of Medical Science, Kermanshah, Iran. Tel: +98.9131560290, Email: Sorbih@yahoo.com

Received: December 20, 2015, Accepted: February 20, 2016, Published: March 2016

iThenticate screening: February 20, 2016, English editing: March 01, 2016, Quality control: March 10, 2016

(C) 2016 The Authors. This is an open access article under the terms of the Creative Commons Attribution-NonCommercialNoDerivs License, which permits use and distribution in any medium, provided the original work is properly cited, the use is non-commercial and no modifications or adaptations are made. 


\section{Introduction}

The development of cancer during recent decades and its damaging effects on physical, affective, spiritual, social, and economic aspects have focused experts' attention on this disease as well as lay people, and they present cancer as this century's major health problem. Twenty-five percent of all cancers in Iranian women are breast cancer as the last reports of Iran community cancer show. Despite clinical developments, breast cancer is still one of the fatal malignancies all over the world $(1,2)$, making up $32 \%$ of all cancers among women (3). Although vast advancements in breast cancer therapy has resulted in better reactions toward therapy and increased longevity of the patients, most of these therapies have side effects and also cause mental-social problems for the patients (4, 5). The mental pressures, reduction of physical, affective, and social operations, sexual function disorders and changing their mental image affect the patients' quality of life and happiness after diagnosis and breast cancer therapy $(6,7)$. The beginning of this current disease is the beginning of a stressful period for women, and neglecting their mental status causes the loss of a sense of control, resulting in feelings of hopelessness, depression, and anxiety. It is possible that the psychological complications threaten the patient's survival by its negative effect on the continuation of the therapy process and post-treatment follow-up (8-10). Thus, along with medical advancements for treating breast cancer, intervention seems necessary in order to increase happiness and decrease the mental pressures of these patients. Many interventions have been presented for improving the mental health of these patients, but those that are short-lived and economical are better. Positive psychotherapy was presented for the first time by Seligman in 2000. This theory, unlike Beck's cognitive behavioral therapy, pays attention to the abilities and positive emotions. Indeed, positive psychotherapy is an objective study of experiences and positive operations of each person $(11,12)$. This method shows great promise for enhancing patients' well-being by means of positive psychotherapy intervention (PPIS). Positive psychotherapy interventions are treatment methods for enhancing positive sentiments, behaviors and cognitions $(13,14)$. This focus on generating positive emotions decreases mental disorders and has positive effects on happiness and quality of life. Other advantages of positive psychotherapy are: 1) it is helpful for depressed patients who don't like using drugs or drugs can't cure them, 2) it is economical and its tasks are easy to do, and 3) intervention doesn't take a long time, and the improvements in the patients' behaviors are fast and don't have lateral complications $(15,16)$. Several studies have been conducted on the effectiveness of positive psychotherapy on different disorders. In 2014, Seyedi-Asl et al. (17) studied the effectiveness of group positive psychotherapy on infertile women's happiness in Iran. The results showed that there was a greater reduction of depression in the treatment group than in the control group. In addition, there were greater increases in happiness in the intervention group than in the control group. Asgharipoor et al. (18) compared the effectiveness of positive psychotherapy and cognitive-behavioral therapy for depressive disorder patients. They discovered that both interventions are effective in reducing depression symptoms and increasing the happiness of the patients, while there were no significant changes in the control group. Another study on the effect of positive psychotherapy was done by means of the Internet, and it was found that depression symptoms were decreased by positive psychotherapy practices (16). Since the effectiveness of positive psychotherapy on the psychological status of patients with cancer has never been studied, we decided to measure the effectiveness of group positive psychotherapy on depression and happiness to determine new ways of enhancing the patients' health.

\section{Material and Methods}

2.1. Trial design

This study was a randomized controlled trial that was conducted from September 10, 2013 to December 25, 2015.

\subsection{Participants}

This clinical trial was conducted in the Oncology Center in Kermanshah in 2014. The explanation of this research's performance methods and its goals were given to women who were referred to the Center to see if they were willing to participate. Therefore, 103 patients agreed to participate, but only 42 were selected after the interviews. From the 42 participants, 21 were assigned randomly to the positive psychotherapy intervention group, and 21 were assigned to the control group. While both groups used their drugs, the experimental group benefited from 10 sessions (1.5 hours weekly) of positive psychotherapy, which the control group did not have. At the end, the invalid data of five members of experimental group and four members of the control group were omitted.

\subsection{Instruments}

The inventories below were used for gathering data. The patients completed these inventories before the first ses sion and after the last session: 
1) Demographic inventory: This inventory was made for gathering information of women with cancer by educational level, age, job, illness time, and ...

2) Beck's depression inventory (BDI-II): This inventory is used to measure depression in adults and in teenagers who have had this problem for at least two weeks (19). This inventory has 21 items, and each item is one graded from 0 to 13, and each individual's score is from 0 to 63. Four groups were established based on the ranges of scores as 0-13: minimum score, 14-19: mild depression, 20-28: moderate depression, and 29-63: intense depression (20). The alpha coefficient of 0.87 and the test-retest reliability of 0.74 were obtained in the Iranian prescription of this inventory.

3) Oxford happiness inventory (OHI): The Oxford happiness inventory was developed by Hills and Argyle (21). At first, this inventory had 21 items that were derived from converting the depression inventory, and, later, eight additional items were added. Thus, it has 29 items each of which has four choices that are graded from 0 to 3 , and the final score is between 0 and 87 . Getting a higher score on the happiness inventory shows that there is more happiness in that person's life. A Cronbach's alpha of 0.92 and the testretest reliability of 0.73 were obtained in the Iranian prescription of this inventory.

\subsection{Selection criteria}

The final criteria for choosing individuals were: 1) gaining equivalent score of mild to moderate depression (14-28 in BDI-II), 2) being 25-50 years old, and 3) having had breast cancer for at least 3 months. Also, the exclusion criteria were: 1) intense depression score or lack of depression and 2) receiving simultaneous psychiatry therapy or other psychotherapies.

\subsection{Interventions}

Positive psychotherapy is task-oriented. Each session of group positive psychotherapy has two parts; the first is reviewing previous tasks, and the second is discussing the next task. Each weekly session takes one and a half hours. Welcome and presentation are done at the first session, after which a positive introduction is presented, and the rules are explained (Table 1).

Table 1. Method of group positive psychotherapy

\begin{tabular}{|l|l|}
\hline Session 1 & Using abilities \\
\hline Sessions 2, 3 & Gratitude visit \\
\hline Sessions 4, 5 & Active replying \\
\hline Sessions 6, 7 & Counting gifts \\
\hline Sessions 8, 9 & Taste with relish / Biography \\
\hline Session 10 & Completion and preserving treatment's effects, giving some easy tasks to be done. \\
\hline
\end{tabular}

\subsection{Outcomes}

The primary outcomes of our analysis were the rate of depression and happiness in patients with breast cancer. Also, the secondary outcome from the analysis was the effectiveness of positive psychotherapy on depression and happiness in the patients.

\subsection{Statistical methods}

SPSS-16 was used to analyze the data. The Kolmogorov-Smirnov (K-S) test was used to measure the normalization of the quantitative data, and the results showed that all variables had normal distributions. Also, chi-squared and multivariate analyses of covariance (MANCOVA) were used in this research.

\subsection{Research ethics}

This study was approved by the Moral Committee at Kermanshah University of Medicine Science with the number of 5392 and was recorded in the Iranian Registry of Clinical Trials by the code of IRCT2013101410063N4. Written testimonials were provided by all patients, and all of the data were coded and kept in a safe place.

\section{Results}

Five members of the experimental group and four members of the control group did not participate in posttest, so their results were omitted. The mean age of the 33 participants was $36.63 \pm 5.53$ years. The mean and standard deviation of the experimental group were $36.6 \pm 6.4$ years, and they were $37.23 \pm 4.7$ years for the control group. Chi-squared was used to evaluate the consistency of the qualitative data (demographic features), and the results showed that there was no significant difference between the two groups in age, educational level, and jobs, so it was 
concluded that these two groups were the same in demographic variables (Table 2). The covariance results on the experimental group's posttest showed reduction in depression compared to the pretest; the mean scores of depression of the control group were the same in the pretest and posttest. Also, there were greater levels of happiness in the experimental group posttest than in the pretest or the posttest of the control group. The results showed that there was a significant difference between experimental and control groups for the dependent variables at the level of $\mathrm{p}<0.001$. Thus, there was a significant difference at least in one of the dependent variables (depression, happiness) in both groups. Multivariable covariance analysis of MANCOVA on the dependent variable was done to study the difference, and the results were presented. Table 3 shows the results of the MANCOVA analysis to compare the means of both dependent variables (depression, happiness) by controlling pretests. Thus, Table 3 shows that the MANCOVA analysis was significant in the depression variable $(\mathrm{p}<0.001, \mathrm{~F}=22.4)$ and the happiness variable $(\mathrm{p}<0.001, \mathrm{~F}=39.93)$. Thus, the research hypotheses about the effectiveness of group positive psychotherapy in reducing depression and enhancing happiness among breast cancer patients were confirmed.

Table 2. Demographic comparison of the experimental and control groups by means of chi-squared $(n=33)$

\begin{tabular}{|c|c|c|c|c|c|c|c|c|}
\hline \multirow[t]{2}{*}{ Variable } & \multirow[t]{2}{*}{ Classification } & \multicolumn{2}{|c|}{$\begin{array}{l}\text { Experimental } \\
\text { Group }\end{array}$} & \multicolumn{2}{|c|}{ Control Group } & \multicolumn{2}{|c|}{ Total } & \multirow[t]{2}{*}{$\mathrm{p}$-value } \\
\hline & & $\mathrm{n}$ & $\%$ & $\mathrm{n}$ & $\%$ & $\mathrm{n}$ & $\%$ & \\
\hline \multirow[t]{3}{*}{ Age (year) } & $24-32$ & 6 & 37.5 & 4 & 23.5 & 10 & 30.3 & \multirow[t]{3}{*}{$>0.482$} \\
\hline & $33-41$ & 7 & 43.8 & 11 & 64.7 & 18 & 54.5 & \\
\hline & $42-50$ & 3 & 18.8 & 2 & 11.8 & 5 & 15.2 & \\
\hline \multirow{3}{*}{$\begin{array}{l}\text { Educational } \\
\text { level }\end{array}$} & Under High school & 7 & 43.8 & 7 & 41.2 & 14 & 42.4 & \multirow[t]{3}{*}{$>0.700$} \\
\hline & High school diploma & 7 & 43.8 & 6 & 35.3 & 13 & 39.4 & \\
\hline & College & 2 & 12.6 & 4 & 23.5 & 6 & 18.2 & \\
\hline \multirow[t]{3}{*}{ Job } & Housewife & 9 & 56.3 & 8 & 47.1 & 17 & 51.5 & \multirow[t]{3}{*}{$>0.706$} \\
\hline & Self-employed & 5 & 31.3 & 5 & 29.4 & 10 & 30.3 & \\
\hline & Employee & 2 & 12.4 & 4 & 23.5 & 6 & 18.2 & \\
\hline
\end{tabular}

Table 3. Mean results of MANCOVA on depression and happiness in the experimental and control groups

\begin{tabular}{|l|l|l|l|l|l|l|l|}
\hline \multirow{2}{*}{ Variables } & \multicolumn{2}{|l|}{ Experimental Group $^{\text {a }}$} & \multicolumn{2}{l|}{ Control Group $^{\text {a }}$} & Mean & F & Sig. \\
\cline { 2 - 8 } & Pretest $^{\mathrm{b}}$ & Posttest $^{\mathrm{b}}$ & Pretest $^{\mathrm{b}}$ & Posttest $^{\mathrm{b}}$ & Squares & & \\
\hline Depression & $20.93 \pm 6.25$ & $14.18 \pm 5.47$ & $19.23 \pm 4.7$ & $20.11 \pm 5.08$ & 227.5 & 22.4 & $<0.001$ \\
\hline Happiness & $30.56 \pm 10.9$ & $41.12 \pm 11.53$ & $25.3 \pm 4.45$ & $25.17 \pm 4.45$ & 624.4 & 39.93 & $<0.001$ \\
\hline
\end{tabular}

a: number of participants: experimental group $(n=16)$, control group $(n=17)$, b: standard deviation \pm mean

\section{Discussion}

The results showed a significant reduction in depression among the breast cancer patients, but this enhancement was not significant in comparison to the control group. These results were in agreement with those of Seligman et al. (12) and Seyedi-Asl et al. (17). For example, Senf and Liau (22) showed reduced depression among 122 participants by the use of positive psychotherapy intervention in their research. Seligman designed positive psychotherapy assignments to decrease depression. For example, his 'three good things' assignment neutralized the obsessive rumination of depressed patients about negative events. Gratitude visits can change patients' minds about aspects of their negative past relationships, allowing them to enjoy the good things their families had done for them (12). Despite cognitive, behavioral, and interpersonal approaches that focus on decreasing depression, positive approaches accomplish this by increasing positive emotions indirectly $(14,16)$. The results showed that group positive psychotherapy caused significant enhancement of happiness among breast cancer patients, and the same was true for the control group. The results on happiness were in agreement with those of Asgharipoor et al. (18) and Senf and Liau (22). Also Ruini et al. (23) and Wing, Schutte, and Byrne (24) obtained the same results in their study about the effectiveness of positive psychotherapy intervention on life satisfaction and mental well-being (23, 24). Happiness has three items, i.e., positive emotion, engagement, and meaningfulness in Seligman's opinion. Several ways exists for gaining happiness, and the first one is positive emotion, which exists at three times for each person, as described below:

1) The past positive emotion: Gratitude and Mercifulness

2) The present positive emotion: Tasting, Enjoying, and Mindfulness

3) The future positive emotion: Hopefulness and Optimism 
The second way for gaining happiness is doing joyful activities, and the last part of happiness is having goals that cause enthusiasm toward life. Indeed, positive psychotherapy has designed some related assignments to increase happiness. There were several limitations in the present study that should be noted and taken into consideration when interpreting the results, as well as to provide direction for future study, such as:

1) Extension limitation because of research's sample group limitation

2) Lack of control group for controlling therapy's unspecified factors

3) Treatment carried out for just a short time (10 weeks)

\section{Conclusions}

In some recent studies, the effectiveness of positive psychotherapy on depression and happiness was measured, but this study just surveyed the effectiveness of positive psychotherapy intervention on breast cancer patients. The results showed the effectiveness of this therapy in reducing depression and enhancing the mental status of breast cancer patients. Since positive psychotherapy, irrespective of other psychotherapies, pays attention to both the negative and positive aspects of emotions, the quality of the treatment is better than other approaches. This therapy is very affordable for patients. Also, this therapy can be used in oncology centers to enhance physical and mental status of patients.

\section{Acknowledgments:}

This paper was extracted from Mr. Dowlatabadi's postgraduate thesis. It was done employees of Kermanshah University of Medical Sciences and Imam Reza Hospital. The authors gratefully acknowledge the supporters and patients with cancer who helped with the compilation of some of the data.

\section{Trial registration:}

The trial is registered at the Iranian Registry of Clinical Trial (IRST) with the identification number IRCT2013101410063N4.

\section{Funding:}

The authors received financial support for the research from Kermanshah University of Medical Sciences.

\section{Conflict of Interest:}

There is no conflict of interest to be declared.

Authors' contributions:

All authors contributed to this project and article equally. All authors read and approved the final manuscript.

\section{References}

1) Chalmers KI, Luker KA. Breast self-care practices in women with primary relatives with breast cancer. J Adv Nurs. 1996; 23(6): 1212-20. doi: 10.1046/j.1365-2648.1996.12820.x, PMID: 8796471.

2) Chalmers KI, Luker KA, Leinster SJ, Ellis I, Booth K. Information and support needs of women with primary relatives with breast cancer: development of the Information and Support Needs Questionnaire. J Adv Nurs. 2001; 35(4): 497-507. doi: 10.1046/j.1365-2648.2001.01866.x, PMID: 11529948.

3) Tokkaya S, Karayurt O. Adaptation of the Information and Support Needs Questionnaire into Turkish to use in women with primary relatives with breast cancer. Cancer nurs. 2010; 33(2): 119-26. doi: 10.1097/NCC.0b013e3181a92658, PMID: 20142747.

4) Chujo M, Kigawa J, Okamura H. Psychological Factors and Characteristics of Recurrent Breast Cancer Patients with or without Psychosocial Group Therapy Intervention. Yonago Acta Med. 2011; 54(4): 65-74. PMID: 24031131, PMCID: 3763793.

5) Carayol M, Bernard P, Boiche J, Riou F, Mercier B, Cousson-Gelie F, et al. Psychological effect of exercise in women with breast cancer receiving adjuvant therapy: what is the optimal dose needed? Ann oncol. 2013; 24(2): 291-300. PMID: 23041586.

6) Lizama N, Rogers P, Thomson A, Slevin T, Fritschi L, Saunders C, et al. Women's beliefs about breast cancer causation in a breast cancer case-control study. Psycho-oncology. 2016; 25(1): 36-42. doi: 10.1002/pon.3869, PMID: 26087031.

7) Taira N, Iwata H, Hasegawa Y, Sakai T, Higaki K, Kihara K, et al. Health-related quality of life and psychological distress during neoadjuvant endocrine therapy with letrozole to determine endocrine 
responsiveness in postmenopausal breast cancer. Breast Cancer Res Treat. 2014; 145(1): 155-64. PMID: 24692082.

8) De Ver Dye T, Bogale S, Hobden C, Tilahun Y, Hechter V, Deressa T, et al. A mixed-method assessment of beliefs and practice around breast cancer in Ethiopia: implications for public health programming and cancer control. Global public health. 2011; 6(7): 719-31. PMID: 20865612.

9) Henselmans I, Sanderman R, Helgeson VS, de Vries J, Smink A, Ranchor AV. Personal control over the cure of breast cancer: adaptiveness, underlying beliefs and correlates. Psycho-oncology. 2010; 19(5): 52534. PMID: 19557825.

10) Carlson LE, Tamagawa R, Stephen J, Doll R, Faris P, Dirkse D, et al. Tailoring mind-body therapies to individual needs: patients' program preference and psychological traits as moderators of the effects of mindfulness-based cancer recovery and supportive-expressive therapy in distressed breast cancer survivors. J Natl Cancer Inst Monogr. 2014; 2014(50): 308-14. doi: 10.1093/jncimonographs/lgu034, PMID: 25749597.

11) Duckworth AL, Steen TA, Seligman ME. Positive psychology in clinical practice. Annu Rev Clin Psychol. 2005; 1: 629-51. PMID: 17716102 .

12) Seligman ME, Steen TA, Park N, Peterson C. Positive psychology progress: empirical validation of interventions. Am Psychol. 2005; 60(5): 410-21. doi: 10.1037/0003-066X.60.5.410, PMID: 16045394.

13) Sin NL, Lyubomirsky S. Enhancing well-being and alleviating depressive symptoms with positive psychology interventions: a practice-friendly meta-analysis. J Clin Psychol. 2009; 65(5): 467-87. doi: 10.1002/jclp.20593, PMID: 19301241.

14) Schotanus-Dijkstra M, Drossaert CH, Pieterse ME, Walburg JA, Bohlmeijer ET. Efficacy of a Multicomponent Positive Psychology Self-Help Intervention: Study Protocol of a Randomized Controlled Trial. JMIR Res Protoc. 2015; 4(3): e105. doi: 10.2196/resprot.4162, PMID: 26293678.

15) Layous K, Chancellor J, Lyubomirsky S, Wang L, Doraiswamy PM. Delivering happiness: translating positive psychology intervention research for treating major and minor depressive disorders. J Altern Complement Med. 2011; 17(8): 675-83. PMID: 21721928.

16) Seligman ME, Rashid T, Parks AC. Positive psychotherapy. The Am psychol. 2006; 61(8): 774-88. doi: 10.1037/0003-066X.61.8.774, PMID: 17115810.

17) Seyedi-Asl ST, Sadeghi K, Bakhtiari M, Khazaie H, Rezaei M, Ahmadi SM. The Effectiveness of Group Positive Psychotherapy on Improving the Depression and Increasing the Happiness of the Infertile Women: Clinical Trial. Pelagia Research Library. 2014; 4(3): 269-75.

18) Asgharipoor N, Asgharnejad Farid A, Arshadi H, Sahebi A. A comparative study on the effectiveness of positive psychotherapy and group cognitive-behavioral therapy for the patients suffering from major depressive disorder. Iran J Psychiatry Behav Sci. 2012; 6(2): 33-41. PMID: 24644480, PMCID: 3940016.

19) Beck AT, Guth D, Steer RA, Ball R. Screening for major depression disorders in medical inpatients with the Beck Depression Inventory for Primary Care. Behav Res Ther. 1997; 35(8): 785-91. doi: 10.1016/S0005-7967(97)00025-9, PMID: 9256522.

20) Dolle K, Schulte-Korne G, O'Leary AM, von Hofacker N, Izat Y, Allgaier AK. The Beck depression inventory-II in adolescent mental health patients: cut-off scores for detecting depression and rating severity. Psychiatry Res. 2012; 200(2-3): 843-8. doi: 10.1016/j.psychres.2012.05.011, PMID: 22657953.

21) Hills P, Argyle M. The Oxford Happiness Questionnaire: A compact scale for the measurement of psychological well-being. Personality and individual differences. 2002; 33(7): 1073-82. doi: 10.1016/S0191-8869(01)00213-6.

22) Senf K, Liau AK. The effects of positive interventions on happiness and depressive symptoms, with an examination of personality as a moderator. J Happiness Stud. 2013; 14(2): 591-612. doi: 10.1007/s10902012-9344-4.

23) Ruini C, Belaise C, Brombin C, Caffo E, Fava GA. Well-being therapy in school settings: a pilot study. Psychother psychosom. 2006; 75(6): 331-6. doi: 10.1159/000095438, PMID: 17053333.

24) Wing JF, Schutte NS, Byrne B. The effect of positive writing on emotional intelligence and life satisfaction. J Clin Psychol. 2006; 62(10): 1291-302. doi: 10.1002/jclp.20292, PMID: 16810662. 